\title{
Drug Hypersensitivity: How Drugs Stimulate T Cells via Pharmacological Interaction with Immune Receptors
}

\author{
Werner J. Pichler ${ }^{a}$ Jacqueline Adam ${ }^{a}$ Stephen Watkins ${ }^{c}$ Natascha Wuillemin ${ }^{b}$ \\ James Yun ${ }^{d}$ Daniel Yerly ${ }^{b}$ \\ ${ }^{a} \mathrm{ADR}-\mathrm{AC} \mathrm{GmbH}$, and ${ }^{\mathrm{b}} \mathrm{Clinic}$ of Rheumatology and Clinical Immunology/Allergology, University Hospital of Bern, \\ Bern, Switzerland; ' Department of Botany and Plant Pathology, Oregon State University, Corvallis, Oreg., USA; \\ dDepartment of Clinical Immunology, Royal Prince Alfred Hospital, Sydney, N.S.W., Australia
}

\section{Key Words}

$p$-i concept $\cdot p-i$ HLA $\cdot p-i$ TCR $\cdot$ Allo reactivity .

Costimulation

\begin{abstract}
Small chemicals like drugs tend to bind to proteins via noncovalent bonds, e.g. hydrogen bonds, salt bridges or electrostatic interactions. Some chemicals interact with other molecules than the actual target ligand, representing so-called 'off-target' activities of drugs. Such interactions are a main cause of adverse side effects to drugs and are normally classified as predictable type $A$ reactions. Detailed analysis of drug-induced immune reactions revealed that off-target activities also affect immune receptors, such as highly polymorphic human leukocyte antigens (HLA) or T cell receptors (TCR). Such drug interactions with immune receptors may lead to $T$ cell stimulation, resulting in clinical symptoms of delayed-type hypersensitivity. They are assigned the 'pharmacological interaction with immune receptors' ( $p$-i) concept. Analysis of $p$-i has revealed that drugs bind preferentially or exclusively to distinct HLA molecules ( $p$-i HLA) or to distinct TCR ( $p$-i TCR). P-i reactions differ from 'conventional' off-target drug reactions as the outcome is not due to the effect on the drug-modified cells themselves, but is the con-
\end{abstract}

sequence of reactive T cells. Hence, the complex and diverse clinical manifestations of delayed-type hypersensitivity are caused by the functional heterogeneity of T cells. In the abacavir model of $p-i$ HLA, the drug binding to HLA may result in alteration of the presenting peptides. More importantly, the drug binding to HLA generates a drug-modified HLA, which stimulates T cells directly, like an allo-HLA. In the sulfamethoxazole model of $p$-i TCR, responsive T cells likely require costimulation for full T cell activation. These findings may explain the similarity of delayed-type hypersensitivity reactions to graft-versus-host disease, and how systemic viral infections increase the risk of delayed-type hypersensitivity reactions.

C 2015 The Author(s)
Published by S. Karger AG, Basel

\section{Introduction}

Drug hypersensitivity reactions (DHR) are the result of immune interactions with small molecular compounds or proteins used as drugs [1]. Immune reactions to proteins, which represent complete antigens per se, are not discussed here [2]. Reactions to small molecules include allergic, pharmacological (p-i) and nonallergic ('pseudoallergic') hypersensitivity reactions.

\begin{tabular}{ll}
\hline KARGER 125/35 & $\begin{array}{l}\text { C } 2015 \text { The Author(s) } \\
\text { Published by S. Karger AG, Basel }\end{array}$ \\
& $1018-2438 / 15 / 1681-0013 \$ 39.50 / 0$ \\
E-Mail karger@karger.com & This article is licensed under the Creative Commons Attribution- \\
www.karger.com/iaa & NonCommercial-NoDerivatives 4.0 International License (CC BY- \\
& NC-ND) (http://www.karger.com/Services/OpenAccessLicense). \\
& Usage and distribution for commercial purposes as well as any dis- \\
& tribution of modified material requires written permission.
\end{tabular}

Correspondence to: Prof. Dr. Werner J. Pichler

ADR-AC GmbH

Holligenstrasse 91

CH-3008 Bern (Switzerland)

E-Mail werner.pichler@adr-ac.ch 
Table 1. Immune/allergic and pharmacological hypersensitivity reactions

\begin{tabular}{|c|c|}
\hline Hapten concept (immune/allergic stimulation) & p-i concept (pharmacological stimulation) \\
\hline $\begin{array}{l}\text { Generation of a complex immune response with } \\
\text { activation of the innate immune system, T and B } \\
\text { cell reactions }\end{array}$ & $\begin{array}{l}\text { Direct and exclusive T cell stimulation by } \\
\text { 'pharmacological' drug-receptor interaction; innate } \\
\text { immune system not involved }\end{array}$ \\
\hline $\begin{array}{l}\text { Chemical (covalent) stable binding of drug/drug } \\
\text { metabolite to proteins or peptides, which act as } \\
\text { antigens for B and T cells }\end{array}$ & $\begin{array}{l}\text { Structural binding of drug/drug metabolite to certain } \\
\text { HLA or TCR proteins; mostly quite labile interactions }\end{array}$ \\
\hline $\begin{array}{l}\text { Can be dependent on the metabolism of the drug } \\
\text { to reactive compound and needs processing of } \\
\text { proteins to immunogenic peptides }\end{array}$ & $\begin{array}{l}\text { Metabolism of drugs or processing of proteins are not } \\
\text { required to elicit reactivity }\end{array}$ \\
\hline $\begin{array}{l}\text { Time for drug metabolism and protein processing } \\
\text { within APC is needed }(>\sim 4 \mathrm{~h})\end{array}$ & Mostly immediate $(<\sim 10 \mathrm{~min})$ reactivity of T cells ${ }^{1}$ \\
\hline $\begin{array}{l}\mathrm{B} \text { and } \mathrm{T} \text { cells react via specific immune receptors } \\
\text { to drug-modified proteins or drug-modified } \\
\text { peptides }\end{array}$ & $\begin{array}{l}\text { T cells react via TCR directly to the drug-modified } \\
\text { HLA/peptide complex, or the drug has an allogeneic } \\
\text { effect on TCR which then reacts to the HLA peptide }\end{array}$ \\
\hline
\end{tabular}

Allergic, immune-mediated reactions are based on the covalent binding of small chemicals to protein or peptide molecules, which generates new antigenic determinants consisting of either hapten-protein or hapten-peptide complexes [3,4]. These complexes have an immunostimulatory potential since they provide antigenic epitopes to $\mathrm{B}$ cells and immunoglobulins. Processing of these complexes may furthermore generate antigenic hapten-peptides which have the ability to stimulate T cells in a human leukocyte antigen (HLA)-dependent manner. Importantly, haptens can also stimulate innate immunity and activate dendritic cells, meeting an important requirement for the induction of a novel immune response [5-7].

Pharmacological hypersensitivity reactions according to the $\mathrm{p}-\mathrm{i}$ (pharmacological interaction with immune receptor) concept are based on the noncovalent binding of drugs or metabolites to immune receptor proteins themselves (HLA or T cell receptors, TCR) [8-11]. The binding of a drug to an immune receptor follows the same rules as a drug binding to a nonimmunological receptor. Typically, drug binding to a receptor is rapid, based on noncovalent interactions and is reversible [10]. Drug hypersensitivity reactions (DHR) according to the $\mathrm{p}-\mathrm{i}$ concept do not require the processing of a new antigenic complex and neither metabolism of the drug nor subsequent processing steps are required (table 1). In pharma- cological hypersensitivity, complex immune responses encompassing dendritic cell activation and subsequent stimulation of $\mathrm{B}$ and $\mathrm{T}$ cells do not occur. Rather, a typical feature of $\mathrm{p}$-i stimulation is its restriction to $\mathrm{T}$ cells alone as the drugs bind to immune receptors involved in $\mathrm{T}$ cell activation [12]. The final result of $\mathrm{p}$-i stimulation is similar to allergic immune-mediated $\mathrm{T}$ cell reactions and can lead to a quite heterogeneous clinical picture [12].

Pseudo-allergic or nonallergic hypersensitivity reactions are characterized by direct drug interactions with inflammatory effector cells, in particular mast cells, basophils and eosinophils, and probably also neutrophils. In response to a drug, inflammatory cells degranulate or produce and release a large amount of inflammatory mediators, such as leukotrienes. In contrast to allergic and pharmacological stimulations, there is no evidence that the adaptive immune system is involved. Clinically, the most frequent form of pseudoallergic reactions are due to NSAIDs where rapid onset of either cutaneous manifestations (e.g. urticaria or angioedema) or respiratory manifestations (e.g. rhinosinusitis or bronchospasm) occur [13]. In NSAID-triggered reactions a shift to enhanced leukotriene production has been described, but for most pseudoallergic reactions the underlying mechanisms are unknown and probably differ between different drugs and drug classes. In some pseudoallergic or nonallergic 

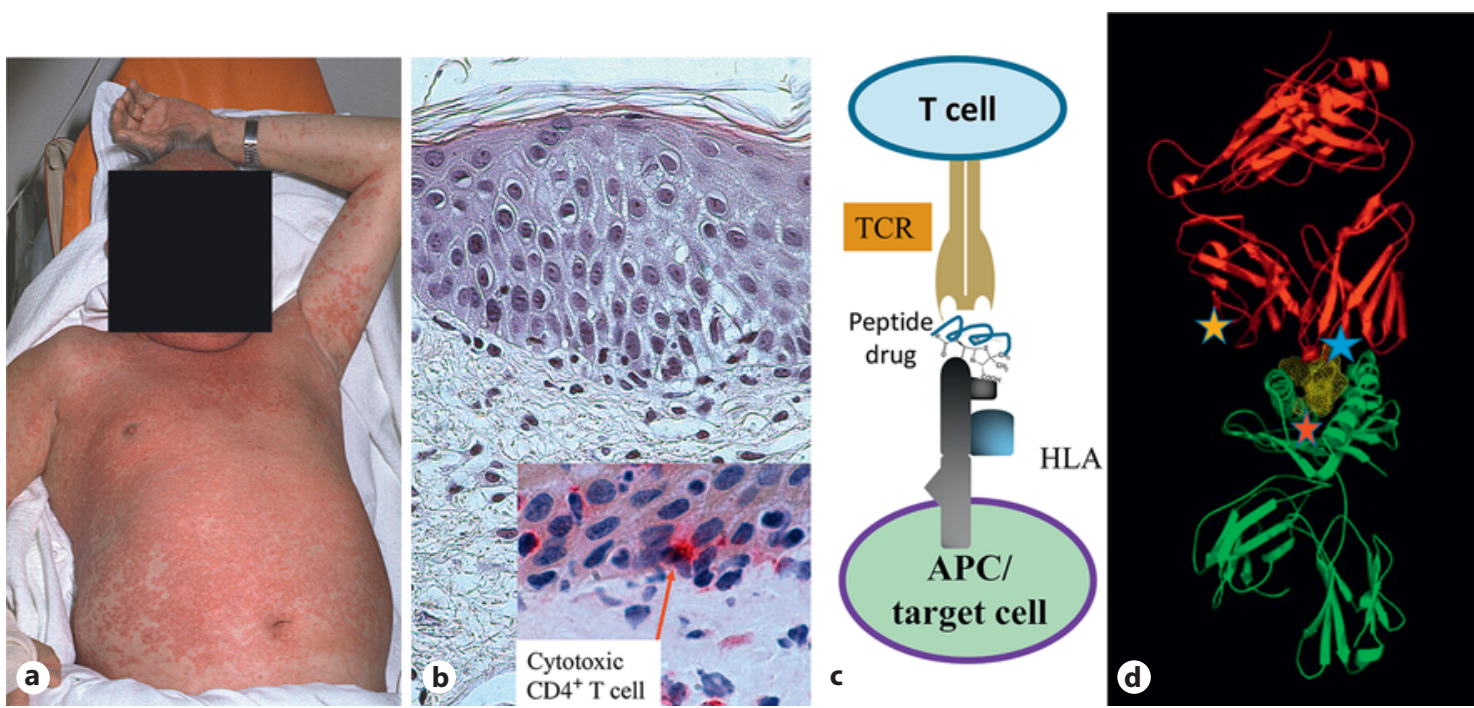

Fig. 1. Drug hypersensitivity: from clinic to molecular models. a A patient with a maculopapular drug eruption. b Histology of T cell infiltration into the dermis and epidermis, and killing of keratinocytes by cytotoxic T cells (red = granzyme B staining of infiltrating $\mathrm{T}$ cells). $\mathbf{c}$ Scheme of the interaction of T cell/TCR with the drug-

hypersensitivity reactions, the drug is cationic and can interact with a human G-protein-coupled receptor, MRGPRX2, on mast cells and lead to IgE-independent mast cell degranulation [14].

This review focuses on $\mathrm{p}$-i-driven $\mathrm{T}$ cell stimulations which can be differentiated into ' $\mathrm{p}$-i HLA' (drug binding to HLA) and 'p-i TCR' (drug binding to TCR) [15]. The drug binding to immune receptors per se can result in partial $\mathrm{T}$ cell activation where costimulation is required or can result in complete $\mathrm{T}$ cell activation. The later includes the abacavir model of $\mathrm{p}-\mathrm{i}$ HLA where drug binding to the peptide-HLA complex (peptHLA) mimics an allo-allele.

\section{$p-i$ HLA and $p-i$ TCR}

Over the last few years, the interaction of small molecules with immune receptors and its functional consequences have become a fascinating new research topic. Studies of T cells from patients revealed that DHR can be due to direct stimulation of $\mathrm{T}$ cells according to the $\mathrm{p}-\mathrm{i}$ concept [8-11]. The partners involved in the $\mathrm{p}$-i concept are the drug, TCR on T cells, and peptHLA on the target cell, which can be antigen-presenting cells (APC) or any tissue cell expressing HLA (fig. 1). Only the presence of these three components leads to effector functions of
peptHLA complex on the APC/target cell. d Crystallographic structure of TCR (red), HLA class I molecule (green) and embedded peptide (yellow); stars indicate possible binding sites of a drug to the immune receptor protein itself (TCR or HLA, according to the $\mathrm{p}-\mathrm{i}$ concept).

T cells such as proliferation, cytokine secretion and cytotoxicity, and these can result in highly variable clinical pictures [12]. Depending on the preferential binding to either HLA or TCR, two types of $\mathrm{p}-\mathrm{i}$ mechanisms can be discriminated: p-i HLA and p-i TCR [15]. All data regarding $p$ - $i$ HLA and $p-i$ TCR involve $\alpha \beta$-TCR and the subsequent T cell stimulations. Stimulations of B cells or NK cells by noncovalent drug binding to their immune receptors have so far not been demonstrated.

\section{$p$-i HLA}

A decisive step forward in understanding severe, T cell-mediated DHR was the discovery of HLA allele associations with severe DHR [16-20]. These associations have been described for a growing number of drugs [reviewed in 21]. Some of these have almost exclusive associations with certain HLA alleles, providing negative predictive values approximating $100 \%$, while the positive predictive values tend to be low $(<3 \%)$. A notable exception is abacavir hypersensitivity syndrome where about $55 \%$ of HLA-B $* 57: 01^{+}$carriers developed a hypersensitivity reaction upon drug exposure [22].

The relative risk of developing HLA-associated DHR depends on the frequency of the involved allele in a given population. Carbamazepine-induced Stevens-Johnson syndrome/toxic epidermal necrolysis (SJS/TEN) in Han 


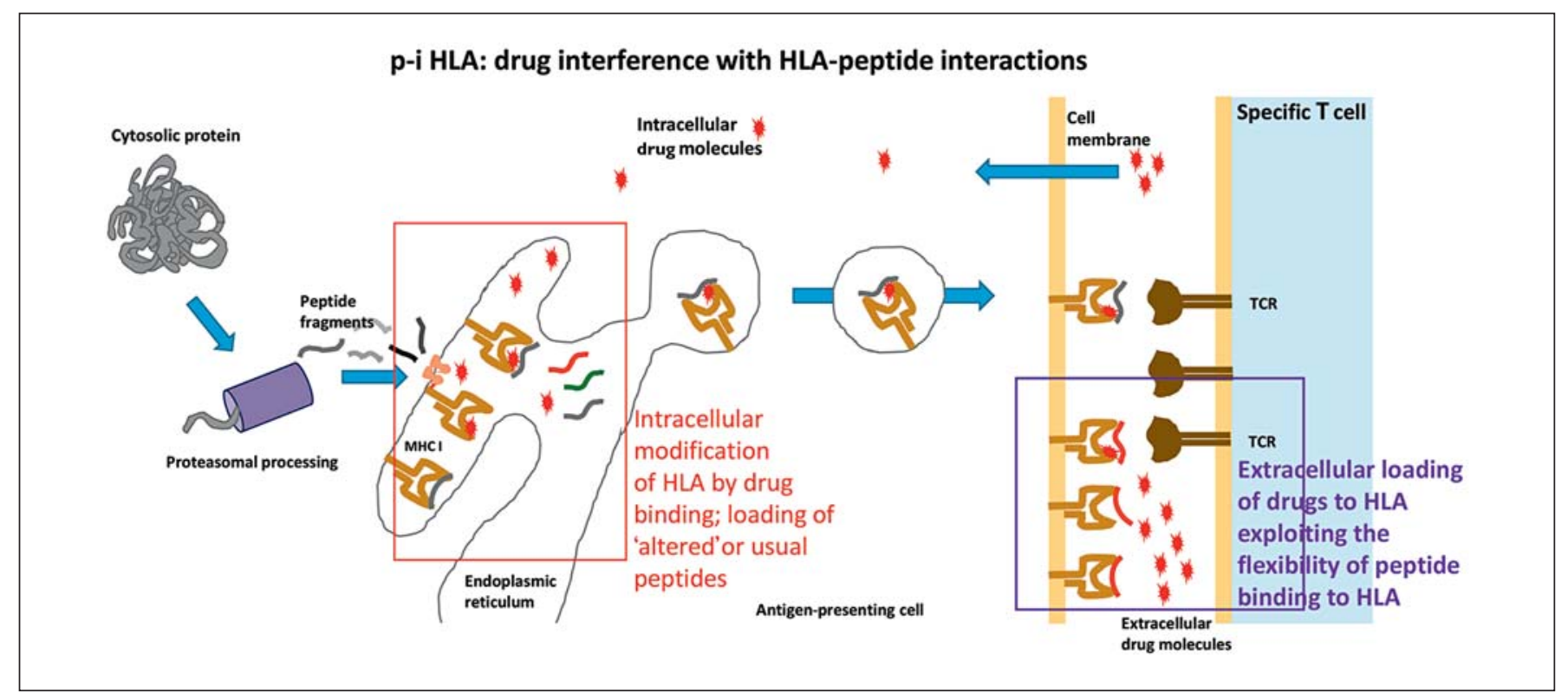

Fig. 2. p-i HLA: modification of HLA-B*57:01 molecules by abacavir occurs via extracellular and intracellular pathways. Via the extracellular pathway, abacavir molecules may directly bind to the F9-pocket of peptHLA-B*57:01 complexes presented on the cell surface. Given the fact that HLA-embedded peptides exhibit a certain degree of flexibility, abacavir could get temporary access to the peptide-binding groove of peptHLA molecules. In order to generate a sufficient number of \{abacavir-peptHLA-B*57:01\} complexes, a relatively high abacavir concentration is required $(10 \mu \mathrm{g} / \mathrm{ml})$ $[35,36]$. Via the intracellular pathway, drug (abacavir) molecules are transported into cells and enter the endoplasmic reticulum, where peptide loading onto the available HLA class I molecules takes place. In the case of abacavir, the drug competes with peptides for the binding to the still empty F9 pocket of HLA-B*57:01. As abacavir seems to have a rather high affinity for the F-pocket,

Chinese were strongly linked to HLA-B*15:02 [17], but this association could not be confirmed in Europeans, where HLA-B*15:02 is rare [23]. In Europeans, carbamazepine-induced hypersensitivity was linked to HLAA*31:01, and mainly manifested as a drug rash with eosinophilia and systemic symptoms (DRESS), and less as SJS/TEN $[23,24]$. In general, the majority of high-risk alleles for DHR were HLA class I, but some less stringent associations were also found for HLA class II alleles [25, 26], mostly resulting in less severe DHR.

In vitro studies revealed that DHR with strong HLA associations were not due to the modification of a peptide by a covalently bound drug or drug metabolite. Neither carbamazepine nor abacavir hypersensitivity peptides eluted from purified HLA molecules of drug-pulsed APC carried a covalently bound drug [27-30]. Indeed, a highly selective quite low abacavir concentrations $(0.01 \mu \mathrm{g} / \mathrm{ml})$ are sufficient to bind to and thus modify a substantial amount of HLA-B*57:01. This has two consequences: (i) the abacavir binding alters the peptide-binding capacity of HLA-B*57:01. In addition and/or instead of usual peptides, altered peptides are selected for binding to \{abacavir-HLA-B*57:01\} [28-30]; (ii) moreover, the abacavir binding makes the \{abacavir-HLA-B*57:01\} complex look like a foreign (allo) HLA-protein. The \{abacavir-peptHLA\} complex is transported to the cell surface, where it elicits an auto- and predominantly an allo-like immune reaction [40]. The stimulation by an abacavir-induced TCC occurs independently of extracellular or intracellular abacavir loading on HLA-B*57:01. This argues for a poly-specificity of the reactive $\mathrm{T}$ cells [35] - not so much the particular peptide but the whole configuration of the abacavirpeptHLA\} complex seems to elicit T cell reactivity $[35,40]$.

HLA allele association argues against the involvement of a hapten-driven T cell stimulation. Haptens bind to multiple binding sites in a protein which, after processing to hapten peptides, would be loaded on different rather than only one HLA molecule [31]. Thus, if a DHR against a distinct molecule is exclusively restricted to a unique HLA allele, it may be argued that the small drug molecule itself rather than a specific peptide is involved.

The Altered Peptide Model of p-i HLA

A breakthrough in understanding the link between DHR and HLA association was the crystallographic structure of the HLA-B*57:01 molecule with bound abacavir $[29,30]$. It showed that the drug binds below the peptide presented by the HLA-B*57:01 molecule, away from the site of peptide-TCR interaction $[28,29]$. Analysis of pep- 
tides eluted from abacavir-treated HLA-B*57:01+ APC revealed that approximately $20 \%$ of the eluted peptides were absent in the pool of peptides eluted from abacaviruntreated HLA-B*57:01 molecules [28-30]. The data suggest that when abacavir is incubated with APC, it is taken up, enters the endoplasmic reticulum, and binds the still empty F-pocket of HLA-B*57:01 via noncovalent bonds (fig. 2,3). This changes the peptide-binding ability of HLA-B*57:01; instead of binding normal HLAB*57:01-anchored peptides with tryptophan at the anchor residue, peptides with a small aliphatic amino acid (valine, isoleucine and leucine) at this position are favored. As such, peptides are novel and are not presented in the absence of abacavir, and they may induce an autoimmune reaction. Therefore, in this altered peptide repertoire model' DHR is a kind of autoimmune reaction [32].

The Allo-Immune Model of p-i HLA

Data for the altered peptide model for DHR rely exclusively on the analysis of abacavir-exposed APC, as altered peptides were not convincingly described in other HLAassociated DHR. The data on carbamazepine are somewhat controversial (see below) $[28,33,34]$. Moreover, the analysis of drug-reactive $\mathrm{T}$ cells induced to abacavir, allopurinol, oxypurinol and flucloxacillin suggest another possibility (fig. 2): drug binding can immediately alter the whole configuration of the peptHLA complex without peptide exchange. All allopurinol/oxypurinol-reacting $\mathrm{T}$ cell clones (TCC), most flucloxacillin-reacting TCC and approximately $40 \%$ of abacavir-reacting TCC reacted immediately $(<5 \mathrm{~min})$ to the respective drugs in the presence of APC as shown by $\mathrm{Ca}^{++}$-influx assays. The speed of this reaction in the reactive $\mathrm{T}$ cells rules out the possibility of internal loading and peptide exchange in the APC [35-37]. How does a drug molecule access its binding site when it is hidden beneath the anchored peptide? The answer may lie in the flexibility of peptHLA complexes. Studies on HLA-B*27:05- and HLA-B*27:09-binding peptides showed that HLA-bound peptides are not always fixed within the binding groove and that some movements out of the groove are possible [38]. Yun et al. [36] proposed that the flexibility of HLA-binding peptides may allow drug binding to the HLA pockets despite the presence of a peptide. Peptide flexibility would lead to partial detachment of the peptide, thereby exposing the drug-binding site. This would allow the drug molecule to bind to the relevant site, e.g. the F-pocket in the peptidebinding groove. This rapidly formed peptide-drug-HLA complex would be immunogenic in a way that is similar to an allo-HLA causing direct allo-recognition by $\mathrm{T}$ cells

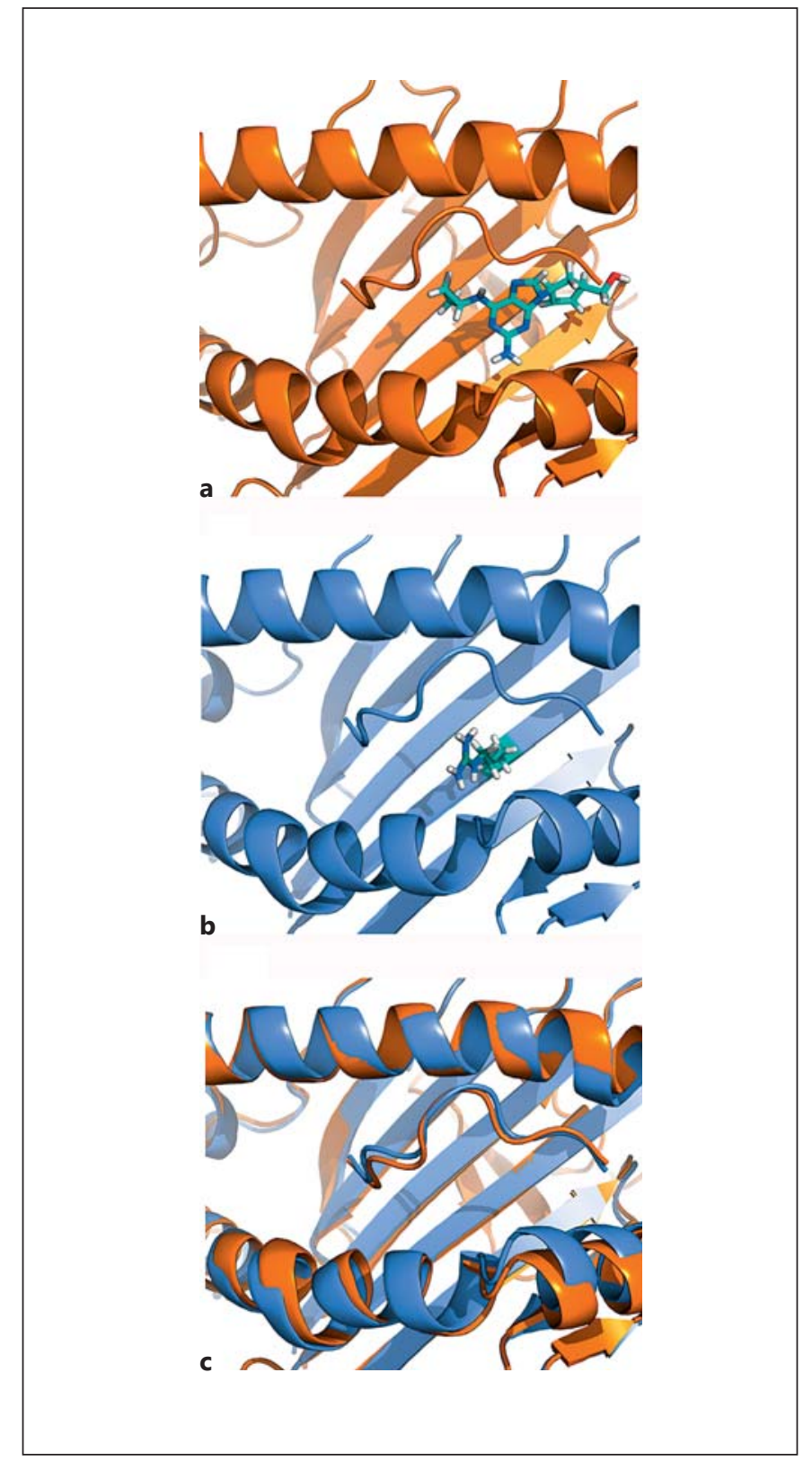

Fig. 3. $p-i$ HLA: abacavir binding to HLA $B * 57: 01$ and its imitation of $\mathrm{B}^{*}$ 58:01: direct allo-stimulation as an explanation for drug hypersensitivity. A model of the peptide-binding groove (F pocket) of HLA-B*57:01 with abacavir docked (a), or HLA-B*58:01 without abacavir (b). The peptide IALYLQQNV was chosen as it is able to bind to both $\mathrm{B}^{*}$ 57:01 (with or without abacavir) as well as $B^{*} 58: 01$ [40]. Note that the abacavir in $B^{*} 57: 01$ provides a bulging of the peptide similar to the arginine of position 96 (shown as a stick model) in $B^{*} 58: 01$. The model explains the cross-reactivity of some abacavir/pept/HLA-B*57:01-induced TCC with B*58:01 [40]. c Overlay of energy-minimized peptides from HLA $B * 57: 01$ plus abacavir (blue) and $\mathrm{B}^{*}$ 58:01 (orange). Minor differences also occur in the $a 2$ helix (lower helix) [for details of binding in the F9pocket, see ref. 28, 29; see ref. 40 for cross-reactivity with HLAB*58:01]. 
Table 2. Comparing allo-immune and drug hypersensitivity reactions

\begin{tabular}{|c|c|c|}
\hline & Allo reactivity (direct) & Drug hypersensitivity (p-i HLA) ${ }^{1}$ \\
\hline Altered HLA & allo-allele & $\begin{array}{l}\text { drug-modified self HLA } \\
\text { acquiring features of an allo HLA-protein }\end{array}$ \\
\hline Direct T cell stimulation & allo-HLA with peptide & $\begin{array}{l}\text { drug-modified HLA with self- or altered } \\
\text { peptide }\end{array}$ \\
\hline $\begin{array}{l}\text { Dendritic cell requirement and } \\
\text { costimulation }\end{array}$ & no & no \\
\hline Stimulation of naïve T cells & yes & yes \\
\hline Stimulation of memory T cells & yes & yes \\
\hline Peptide specificity of TCR & polyspecific $^{2}$ & polyspecific $^{2}$ \\
\hline
\end{tabular}

${ }^{1}$ Investigated mainly in the abacavir model. ${ }^{2} \mathrm{~T}$ cells react with more than one peptide (see text).

[39]. The direct pathway of allo-stimulation results from the recognition of intact, foreign peptide-MHC complexes on the surface of donor cells. Of note, about $5-20 \%$ of circulating $\mathrm{T}$ cells are directly stimulated by an allo-protein and this forms the basis for rapid transplant rejection and acute graft-versus-host disease (GVHD).

This allo-immune concept for DHR was based on a detailed analysis of abacavir-induced TCC [40], which revealed some features similar to direct allo-recognition, where a direct interaction of the TCR with allo-peptHLA results in an immediate $\mathrm{T}$ cell activation [39] (table 2). Adam et al. [40] found that abacavir-stimulated T cells can be induced in the absence of dendritic cells and that they stemmed from both the naïve and memory $\mathrm{T}$ cell pool. The stimulation of naïve $\mathrm{T}$ cells by abacavir was recently confirmed by Lucas et al. [43]. Both features are unusual for 'normal' peptide reactivity, but well documented for direct allo-stimulation [39, 41, 42, 44]. Moreover, when 136 abacavir-reacting TCC from 3 HLA B*57: $01^{+}$donors were analyzed, in each of the donors $5 \%$ of the abacavir-reacting TCC also reacted to HLA-B*58:01-peptide complexes (in the absence of abacavir) [40]. Docking and modeling studies suggested that this allo-reactivity of abacavir reacting TCC was due to the similarity of \{abacavir-pept-B*57:01\} complexes to \{pept-B*5ㅇ:01\} complexes, leading to the assumption that noncovalent drug binding to a self HLA protein (HLA-B*57:01) can transform it to look like an allogeneic HLA protein (namely like HLA-B*58:01; fig. 3). Table 2 summarizes the similarities of allo- and drug stimulations.

An interesting but not yet well documented aspect of abacavir-induced $\mathrm{T}$ cell responses is the polyspecificity of the reactive T cells. Polyspecificity refers to the ability of $\mathrm{T}$ cells to react with more than one peptide. It is assumed to be frequent in allo-reactions $[44,45]$ where the peptides are presented by an allo-allele. It might explain the strength of allo-immune reactions, which by far exceeds the stimulation by a single peptide. Polyspecificity could explain why all TCC, which react immediately to the addition of abacavir \{abacavir-pept-B*57:01\}, always also reacted to abacavir-pulsed APC, where an internal peptide exchange might have taken place [35] (fig. 2). Thus, although surface-presented and internally loaded peptides differ, the TCC reactivity was unchanged. This ability to react with various peptides may also explain the observation that abacavir-induced TCC react similarly to abacavir when a battery of different abacavir-exposed APC (EBV transformed B-LCL, monocytes, phytohemagglutinin-stimulated blasts and HLA-transfected lymphoblastoid cell line 721.221) are used, which most likely present different peptides. Polyspecificity also includes the term heterologous immunity [43], which is used to explain prior priming of $\mathrm{T}$ cells by a viral peptide, for example, followed by reactivation of the same $\mathrm{T}$ cell by a cross-reactive peptHLA or \{peptHLA-drug\} complex [43]. It is hypothesized that such a polyspecific (crossreactive/heterologous) reaction may explain the $\mathrm{T}$ cell reactivity versus, for example, herpes virus-infected tissue, as the drug-induced $\mathrm{T}$ cells may also react with herpes virus pept/HLA in the tissue.

In summary, the model of allo-stimulation by $\mathrm{p}-\mathrm{i}$ HLA provides a novel explanation for the capacity of small molecules to initiate a strong immune response without further cofactors. The connection of direct allo-stimulation and stimulation by $\mathrm{p}-\mathrm{i}$ has already been noted previously as $30 \%$ of drug-induced TCC were found to be alloreactive [46]. This link may also explain why clinical features of SJS/TEN occur not only in DHR, but also in
18

Int Arch Allergy Immunol 2015;168:13-24 DOI: $10.1159 / 000441280$
Pichler/Adam/Watkins/Wuillemin/Yun/ Yerly 
GVHD/organ transplantation [47-51]. However, this concept of direct allo-immune-like stimulation in $\mathrm{p}-\mathrm{i}$ HLA needs to be investigated further, and whether it can be extended to other drugs and HLA-associated DHR has yet to be clarified.

\section{$p-i T C R$}

$\mathrm{p}-\mathrm{i}$ TCR refers to the direct interaction of a drug with $\alpha \beta$-TCR [15]. In early studies with sulfamethoxazole(SMX), lidocaine- and quinolone-reacting TCC- and TCR-transfected hybridoma cells, T cell activation was linked to the unique structure of the drug-reactive TCR. $T$ cell stimulation required the presence of HLA molecules but the immunogenic peptides bound to HLA were exchangeable. Even the HLA molecules were exchangeable, as some TCC maintained reactivity in the presence of allogeneic APC [52-56]. Of note, most of these characteristics were shown for $\mathrm{CD} 4^{+} \mathrm{TCC}$, restricted by MHC class II molecules.

Newer data support and extend these data and lead to at least two models of T cell stimulation by p-i TCR [5759]. Data are based on a detailed analysis of two SMXreacting $\mathrm{CD}^{+}$TCC named 'H13' and ' 1.3 ' (fig. 4) from the same SMX-allergic donor: the two TCC were evaluated regarding proliferation to twelve different sulfanilamides, inhibition of SMX-induced proliferation by other sulfanilamides and by molecular modeling. TCC $\mathrm{H} 13$ is clearly restricted to HLA-DRB $1 * 10: 01$, while TCC 1.3 reacted with SMX even in the absence of APC, i.e. the TCC could self-present the drug [57]. Data of the two TCC revealed that SMX bound to two different sites on the two distinct TCR with rather distinct functional consequences. In the case of TCC H13, SMX binding to the TCR resulted in allosteric interactions [58]. SMX and five of the eleven other sulfanilamides tested were stimulatory in proliferation assays. These were found to bind outside the peptide interacting site on the TCRCDR2 of the $\beta$-chain. The remaining six sulfanilamides did not bind at all (as revealed by docking), and were not stimulatory. Molecular modeling of SMX binding to the TCR revealed that SMX bound to the CDR2 region of TCR-V $\beta 20-1$. This binding induces an alteration of the TCR configuration which results in an increased affinity of TCR H13 to the HLA-DRB1*10:01 and a lamininderived peptide (Gibbs energy between the TCR and pept-HLA were 7-fold higher with SMX compared to without SMX). Thus, drug binding to TCR can result in an allosteric effect which enhances the reactivity of a TCR to HLA with presented (self) peptides [58] (fig. 4).

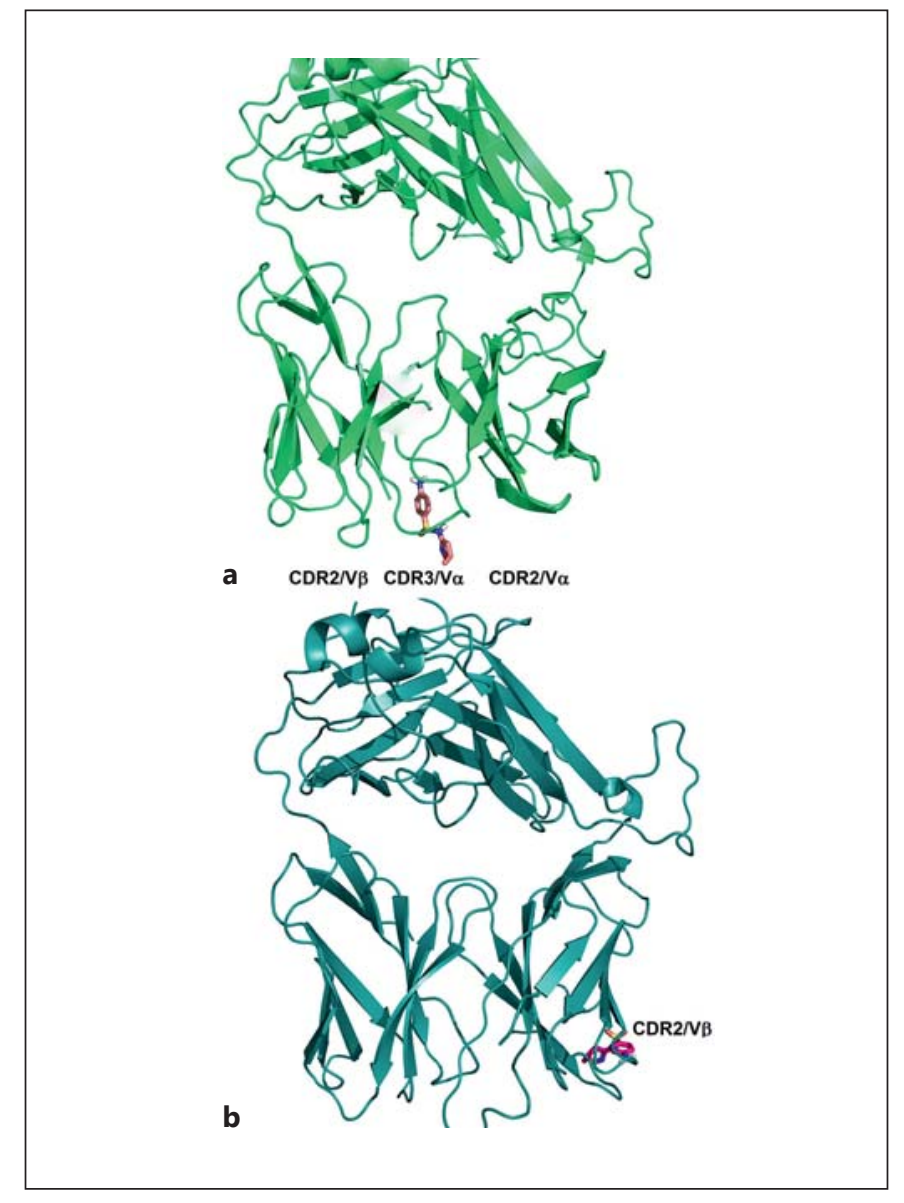

Fig. 4. p-i TCR: SMX binding to 1.3 (a) and H13 (b). a The binding site of SMX could be localized by docking to the CDR3/Va of the TCR 1.3. Eleven other sulfanilamides were also localized by docking to the same position at CDR3/Va, but these eleven sulfanilamides were not stimulatory. They were, however, able to inhibit the SMX-induced $\mathrm{Ca}^{++}$influx and proliferation in TCC 1.3, which confirms their binding to the SMX binding site of TCR 1.3 (fig. 5) [57]. b A model of the TCR H13, with the binding site of SMX on CDR2 of TCR-V $\beta 20-1$. Five other sulfanilamides also bind to the same region. These six sulfanilamides elicit a proliferative response if autologous APCs are present [57]. Molecular modeling revealed that SMX binding to the CDR2 region induces an allosteric effect which increases the binding affinity of the TCR with the peptHLA complex by 7-fold [58].

The elucidation of SMX binding to the second TCR 1.3 resulted in a completely different picture $[57,59]$ (fig. 4, 5). In this case, SMX binds directly to the rather large loop formed by CDR3 of the $a$-chain of the TCR. It stimulates the TCR/TCC similar to a hapten-modified peptide presented by HLA-DR [57, 60]. Interestingly, SMX stimulation of this specific TCC was very strong - often stronger than the stimulation induced by the mitogen phytohe- 


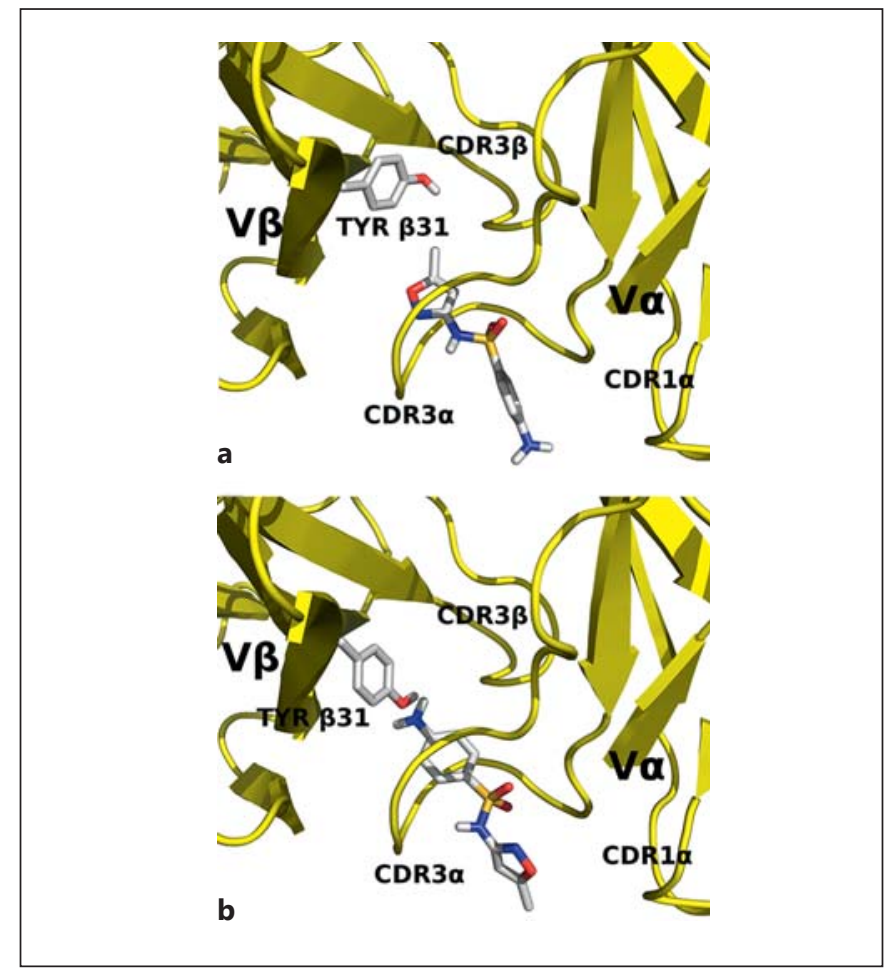

Fig. 5. p-i TCR: orientation of sulfanilamide binding into the CDR3/Va of the TCR 1.3. a The sulfanilamides localize into the large loop of the CDR3/Va of TCR 1.3: the nonstimulatory sulfanilamides had their NH2 ends directed towards the TCR $[57,59]$. b Only the stimulatory SMX can bind to the CDR3/Va in an inverse orientation, with its $\mathrm{NH} 2$ group pointing to the peptidebinding groove [57].

magglutinin. SMX-specific stimulation could be blocked in a dose-dependent way by any of the other eleven sulfanilamides [57]. Docking studies revealed that SMX and the eleven other sulfanilamide derivatives bound to the same binding site on CDR3 $\alpha$, which explains their blocking effect. It also shows that drug binding to TCR may or may not result in T cell activation [57]. Apparently, drug binding without stimulation is more frequent than binding with stimulation, which is similar to other drug-receptor interactions. Why are eleven sulfanilamides nonstimulatory whereas one (SMX) is stimulatory? A closer look suggested that the nonstimulatory sulfonamides bound to the CDR3 a pocket had their NH2 ends directed towards the TCR (fig. 5) $[57,59]$. Only SMX bound to the CDR3 $a$ had its $\mathrm{NH} 2$ group pointing to the peptide-binding groove. This orientation would be similar to the orientation of the hapten SMX-NO when it is bound to a peptide and presented on HLA. Indeed, we and others have already described TCC which react on the one hand with SMX via the $\mathrm{p}$-i mechanism, and on the other hand with the hapten SMX-NO [60, 61]. Earlier data of TCC 1.3 revealed that it also reacted to SMX-NO (unpubl. data). Thus, the docking data of SMX binding to TCR-CDR3a supports and explains the existence of such hapten (SMX-NO) and $\mathrm{p}-\mathrm{i}$ (SMX) cross-reactive TCC. It also shows that, under these stimulatory conditions, the drug molecule itself and not a peptide is recognized. The stimulation of TCR 1.3 was exclusively dependent on SMX without the need for peptide recognition/interaction in combination with a particular HLA [46, 57]. However, an HLA molecule was still required as a matrix. It was thus rather similar to certain stimulations by trinitrophenol molecules which were covalently bound in the middle of immunogenic peptides in mouse models of contact dermatitis, independent of the sequence and MHC allele [62].

\section{Requirements for Costimulation for p-i Stimulations}

Costimulation from innate immunity is a crucial step in the development of a primary adaptive immune response to protein or hapten-modified protein antigens. Indeed, chemicals acting as haptens do not only form neoantigens, but can also activate innate immunity and elicit dendritic cell maturation [5-7].

The cofactors involved in p-i TCR and p-i HLA may differ; no costimulation is required in the abacavir model of p-i HLA as the abacavir-B*57:01-peptide complexes per se act like an allo-allele and elicit a strong and direct T cell stimulation. The discrepancy between $100 \%$ in vitro response to abacavir in HLA-B*57:01 ${ }^{+}$individuals [40, 43,63 ] and only $55 \%$ in vivo reactors [22] might be related to the tolerance mechanism, similar to the tolerance mechanism in transplantation or pregnancy. On the other hand, $\mathrm{p}-\mathrm{i}$ TCR stimulations are different and some may require cofactors. There are at least two possibilities: (a) the presence of the HLA-risk allele may become relevant only when an additional $\mathrm{T}$ cell clonotype is present, and (b) activation of $\mathrm{T}$ cells by concomitant infection with the release of cytokines and upregulation of adhesion molecules may lower the threshold of $\mathrm{T}$ cell reactivity.

The high negative predictive value for carbamazepine hypersensitivity in HLA-B*15:02+ individuals and the low positive predictive value suggested that this allele is a crucial yet not sufficient risk factor for carbamazepine hypersensitivity syndrome [33, 34]. Ko et al. [33] showed that carbamazepine-reacting T cells from HLA-B*15:02 ${ }^{+}$ patients with SJS/TEN used mainly the TCR V $\beta-11$ ISGSY clonotype. This clonotype was present in 16 out of 
19 patients and was absent in all 17 carbamazepine-tolerant patients. Moreover, in PBMC of healthy subjects who are carriers of HLA-B* $15: 02$ and of V $\beta$-11-ISGSY, carbamazepine-specific cytotoxicity could also be primed in vitro. Thus, the data suggest that only if both a certain HLA and a certain TCR-sequence are present, a strong and disease-causing T cell stimulation can develop $[33,34]$.

In $\mathrm{p}-\mathrm{i}$ TCR, the analysis of SMX reactivity of TCC H13 revealed that the binding site on the TCR V $\beta 20.1$ is not unique for a particular individual, but is present in all individuals. Approximately $0.8-2.4 \%$ of normal circulating $\mathrm{T}$ cells express the V $\beta 20.1$. Epidemiology suggests that only around 3\% of SMX-treated individuals develop allergy upon drug exposure [64]. However, during the early years of the HIV epidemic, when patients with HIV infection and T cell immunodeficiency received SMX/trimethoprim (SMX/TMP) as a prophylaxis against opportunistic infections, cutaneous, allergy-like side effects to SMX/ TMP occurred in $30-50 \%$ of treated HIV-positive patients $[65,66]$. 'Sulfa-allergy' is also more prevalent in patients with active autoimmune disease [67]. A possible explanation may lie in the massive immune activation caused by the HIV infection with the upregulation of adhesion molecules, enhanced expression of HLA molecules and increased cytokine production, which lowers the activation threshold of TCR-V $\beta 20.1^{+}$T cells to react to SMX. Thus, while SMX binding to TCR-V $\beta 20.1^{+}$per se is probably insufficient to elicit DHR, the additional presence of generalized immune activation with a lowered threshold for $\mathrm{T}$ cell reactivity may be sufficient for $\mathrm{T}$ cell activation. Of note, not all $\mathrm{p}$-i TCR require costimulation; the binding of SMX to TCR 1.3 may result in activation without costimulation as this stimulation is very strong per se and linked to a particular and rather unique TCR [57].

\section{The p-i Concept: A Particular 'Off-Target' Activity of a Drug}

The features of drug receptor interactions as elucidated in the p-i concept do actually correspond to an 'offtarget' activity of a drug, namely that drugs do not only bind to their intended targets, but also to other proteins/ receptor structures. Such 'off-target' activities may actually occur rather frequently, as these immune receptors are very polymorphic. One estimate is that there are about $10^{11}$ TCR per individual and over 10,000 different HLA class I and more than 3,000 HLA class II alleles in the human population (http://www.allelefrequencies. net/hla6006a.asp). Thus, the chance of a drug finding a suitable binding site within some of the polymorphic immune receptors is probably higher than with monomorphic receptor structures. The majority of such drug-receptor interactions within the immune system may occur without functional consequences. However, a few drugs may bind at a relevant position on the TCR or HLA molecule and be affine enough to cause functional consequences.

To consider the p-i concept as an 'off-target' activity of a drug on immune receptors is intriguing. It is also helpful to emphasize the pharmacological basis of the reaction. However, the 'off-target' activity of a drug on the immune receptor has many - and in particular more complex - implications than the usual off-target reactions on a receptor of a certain tissue cell and, thus, the term p-i concept is justified and should be kept. A main distinction between the $\mathrm{p}$-i concept and usual off-target activities of drugs is the fact that the effect may be indirect. It is not the cell, whose receptor was altered by drug binding, but a reactive $\mathrm{T}$ cell that is responsible for the symptoms. In p-i HLA, it is not the drug-modified APC, but rather the reactive $\mathrm{T}$ cell which causes clinical symptoms by secreting cytokines or mediating cytotoxicity. In $\mathrm{p}-\mathrm{i}$ TCR, the functional consequence is due to an interaction between the T cell and the HLA-peptide complex on APC. In usual off-target activities, the effect is confined to the cells carrying the off-target receptor.

Another complication is the great heterogeneity of the immune system. While usual off-target activities result in a consistent and homogeneous result, the functional consequence of $p$-i TCR or p-i HLA are as complex as the immune system itself. In p-i TCR, not all but only some TCR are activated. It is a drug-receptor-driven stimulation, but it looks like an antigen-driven stimulation. The immune reaction induced is actually a reflection of the available $\mathrm{T}$ cell repertoire and may mirror the prior experience of the individual. The clinical manifestations can be very heterogeneous, with features such as cytotoxic, suppressor, helper, etc. Similarly, in p-i HLA, an allo-like immune response may evolve which is often polyclonal and clinically as heterogeneous as a GVHD reaction.

Last but not least, the complexity of clinical pictures is not only related to drug binding to different immune receptors like HLA, TCR or both TCR and HLA, but differences may also be due to the strength/affinity/exact location of drug binding to the immune receptors involved. All these important distinctions between 'simple' and 'complex' off-target reactions justify keeping the term ' $\mathrm{p}$ - i concept' as a separate entity.

Int Arch Allergy Immunol 2015;168:13-24 DOI: $10.1159 / 000441280$ 


\section{Can Other Endogenous Small Molecules Also Be Involved in Abnormal T Cell Stimulations?}

If small molecules like drugs can under certain circumstances elicit such severe diseases like SJS/TEN or DRESS, is it possible that other endogenous small molecules can under certain circumstances also be harmful? There are two arguments to support this possibility. First, there is the above-mentioned argument that the unique HLA-restriction of certain diseases are better explained by the binding of small-molecule-like drugs to a unique pocket in an incriminated HLA allele rather than by an HLA-presented peptide, as the latter normally also binds to other similar HLA alleles. Second, Yun et al. [36] have described T cell lines which react to xanthine. The reacting $\mathrm{T}$ cells were initiated by oxypurinol, but mounted cytotoxic reactivity also to xanthine, a small endogenous molecule. Therefore, a small, endogenously produced molecule may stimulate an immune reaction under certain circumstances [68]. A potential role of small molecules as a trigger for an immune reaction was hitherto not considered, since they were excluded based on immunological data and exclusive focusing on hapten characteristics. However, small molecules have apparently different ways to stimulate the immune system. Importantly, while a rather exclusive HLA association may be an indication for the involvement of small molecules in a hypersensitivity disease, it is no prerequisite, as some small molecules may bind to various HLA alleles.

\section{Conclusion}

The described features of the $\mathrm{p}-\mathrm{i}$ concept opens a Pandora's box of possible interferences of small molecules with the immune system. Many of the peculiar in vitro, in vivo and clinical features of drug allergies can be explained by $p-i$ TCR and p-i HLA, and this concept may also apply to diseases beyond DHR. However, while the essence of the p-i concept is quite well established, the data and conclusions described in this review are still limited and are mainly based on a detailed analysis of a few drugs. Further verification and extension of p-i interactions with other molecules and analysis of functional consequences is needed.

The link of DHR to an allo-like immune stimulation should remind us of certain limitations of modern medicine. Two main causes of iatrogenic diseases, allotransplant rejection/GVHD and DHR, can be traced back to the same problem, namely how the specific immune system learns to discriminate self from non-self. It shows us that modern medicine introduces new players like organ/ bone marrow transplantation and extensive pharmacotherapy with many novel chemicals into a system that has developed over millions of years, but was never prepared for such 'artificial' interventions. Understanding these limitations may be an important first step and may help to overcome and avoid iatrogenic diseases like DHR. In addition, it may possibly uncover other unknown causes of 'modern' diseases.

\section{Acknowledgements}

The support provided by ADR-AC GmbH in the preparation of this paper is appreciated.

\section{Disclosure Statement}

The authors declare no conflicts of interest.

\section{References}

1 Demoly P, Adkinson NF, Brockow K, Castells M, Chiriac AM, Greenberger PA, Khan DA, Lang DM, Park HS, Pichler W, Sanchez-Borges M, Shiohara T, Thong BY: International consensus on drug allergy. Allergy 2014;69: 420-437.

2 Pichler WJ: Adverse side-effects to biological agents. Allergy 2006;61:912-920.

3 Landsteiner K, Jacobs J: Studies on the sensitization of animals with simple chemical compounds. J Exp Med 1936;64:625-639.

4 Whitaker P, Meng X, Lavergne SN, ElGhaiesh S, Monshi M, Earnshaw C, Peckham D, Gooi J, Conway S, Pirmohamed M, Jenkins
RE, Naisbitt DJ, Park BK: Mass spectrometric characterization of circulating and functional antigens derived from piperacillin in patients with cystic fibrosis. J Immunol 2011;187:200211.

5 Aiba S: Maturation of dendritic cells induced by cytokines and haptens. Tohoku J Exp Med 1998;184:159-172.

6 Arrighi JF, Rebsamen M, Rousset F, Kindler V, Hauser C: A critical role for p38 mitogenactivated protein kinase in the maturation of human blood-derived dendritic cells induced by lipopolysaccharide, TNF- $\alpha$, and contact sensitizers. J Immunol 2001;166:3837-3845.
7 Martin SF: Contact dermatitis: from pathomechanisms to immunotoxicology. Exp Dermatol 2012;21:382-389.

8 Schnyder B, Mauri-Hellweg D, Zanni M, Bettens F, Pichler WJ: Direct, MHC-dependent presentation of the drug sulfamethoxazole to human alphabeta $\mathrm{T}$ cell clones. J Clin Invest 1997;100:136-141.

9 Zanni MP, von Greyerz S, Schnyder B, Brander KA, Frutig K, Hari Y, Valitutti S, Pichler WJ: HLA-restricted, processing- and metabolism-independent pathway of drug recognition by human alpha beta T lymphocytes. J Clin Invest 1998;102:1591-1598. 
10 Pichler WJ: Pharmacological interaction of drugs with antigen-specific immune receptors: the p-i concept. Curr Opin Allergy Clin Immunol 2002;2:301-305.

11 Pichler WJ, Beeler A, Keller M, Lerch M, Posadas S, Schmid D, Spanou Z, Zawodniak A, Gerber B: Pharmacological interaction of drugs with immune receptors: the p-i concept. Allergol Int 2006;55:17-25.

12 Pichler WJ: Delayed drug hypersensitivity reactions. Ann Intern Med 2003;139:683-693.

13 Kowalski ML, Asero R, Bavbek S, Blanca M, Blanca-Lopez N, Bochenek G, Brockow K, Campo P, Celik G, Cernadas J, Cortellini G, Gomes E, Niżankowska-Mogilnicka E, Romano A, Szczeklik A, Testi S, Torres MJ, Wöhrl S, Makowska J: Classification and practical approach to the diagnosis and management of hypersensitivity to nonsteroidal anti-inflammatory drugs. Allergy 2013;68: 1219-1232.

14 McNeil BD, Pundir P, Meeker S, Han L, Undem BJ, Kulka M, Dong X: Identification of a mast-cell-specific receptor crucial for pseudo-allergic drug reactions. Nature 2015;519: 237-241.

15 Adam J, Pichler WJ, Yerly D: Delayed drug hypersensitivity: models of T-cell stimulation. Br J Clin Pharmacol 2011;71:701-707.

16 Mallal S, Nolan D, Witt C, Masel G, Martin AM, Moore C, Sayer D, Castley A, Mamotte C, Maxwell D, James I, Christiansen FT: Association between presence of HLA-B*5701, HLA-DR7, and HLA-DQ3 and hypersensitivity to HIV-1 reverse-transcriptase inhibitor abacavir. Lancet 2002;359:727-732.

17 Chung WH, Hung SI, Hong HS, Hsih MS, Yang LC, Ho HC, Wu JY, Chen YT: Medical genetics: a marker for Stevens-Johnson syndrome. Nature 2004;428:486.

18 Hung SI, Chung WH, Liou LB, Chu CC, Lin M, Huang HP, Lin YL, Lan JL, Yang LC, Hong HS, Chen MJ, Lai PC, Wu MS, Chu CY, Wang $\mathrm{KH}$, Chen CH, Fann CS, Wu JY, Chen YT: HLA-B*5801 allele as a genetic marker for severe cutaneous adverse reactions caused by allopurinol. Proc Natl Acad Sci USA 2005; 102:4134-4139.

19 Daly AK, Donaldson PT, Bhatnagar P, Shen Y, Pe'er I, Floratos A, Daly MJ, Goldstein DB, John S, Nelson MR, Graham J, Park BK, Dillon JF, Bernal W, Cordell HJ, Pirmohamed M, Aithal GP, Day CP; DILIGEN Study; International SAE Consortium: HLA-B*5701 genotype is a major determinant of drug-induced liver injury due to flucloxacillin. Nat Genet 2009;41:816-819.

20 Chang FR, Liu H, Irwanto A, et al: HLA$B^{*} 13: 01$ and the dapsone hypersensitivity syndrome. N Engl J Med 2013;369:16201628.

21 Pavlos R, Mallal S, Ostrov D, Buus S, Metushi I, Peters B, Phillips E: T cell-mediated hypersensitivity reactions to drugs. Annu Rev Med 2015;66:439-454.
22 Mallal S, Phillips E, Carosi G, Molina JM, Workman C, Tomazic J, Jägel-Guedes E, Rugina S, Kozyrev O, Cid JF, Hay P, Nolan D, Hughes S, Hughes A, Ryan S, Fitch N, Thorborn D, Benbow A; PREDICT-1 Study Team: HLA-B*5701 screening for hypersensitivity to abacavir. N Engl J Med 2008;358:568-579.

23 McCormack M, Alfirevic A, Bourgeois S, Farrell JJ, Kasperavičiūtė D, Carrington $M$, Sills GJ, Marson T, Jia X, de Bakker PI, Chinthapalli K, Molokhia M, Johnson MR, O’Connor GD, Chaila E, Alhusaini S, Shianna KV, Radtke RA, Heinzen EL, Walley N, Pandolfo M, Pichler W, Park BK, Depondt C, Sisodiya SM, Goldstein DB, Deloukas P, Delanty N, Cavalleri GL, Pirmohamed M: HLA-A*3101 and carbamazepine-induced hypersensitivity reactions in Europeans. N Engl J Med 2011; 364:1134-1143.

24 Genin E, Chen DP, Hung SI, Sekula P, Schumacher M, Chang PY, Tsai SH, Wu TL, Bellón T, Tamouza R, Fortier C, Toubert A, Charron D, Hovnanian A, Wolkenstein P, Chung WH, Mockenhaupt M, Roujeau JC: HLA-A*31:01 and different types of carbamazepine-induced severe cutaneous adverse reactions: an international study and meta-analysis. Pharmacogenomics J 2014;14:281-288.

25 Singer JB, Lewitzky S, Leroy E, et al: A genome-wide study identifies HLA alleles associated with lumiracoxib-related liver injury. Nat Genet 2010;42:711-714.

26 Vitezica ZG, Milpied B, Lonjou C, et al: HLADRB $1 * 01$ associated with cutaneous hypersensitivity induced by nevirapine and efavirenz. AIDS 2008;22:540-541.

27 Yang CW, Hung SI, Juo CG, Lin YP, Fang WH, Lu IH, Chen ST, Chen YT: HLA-B*1502 bound peptides: implications for the pathogenesis of carbamazepine-induced StevensJohnson syndrome. J Allergy Clin Immunol 2007;120:870-877.

28 Illing PT, Vivian JP, Dudek NL, Kostenko L, Chen Z, Bharadwaj M, Miles JJ, Kjer-Nielsen L, Gras S, Williamson NA, Burrows SR, Purcell AW, Rossjohn J, McCluskey J: Immune self-reactivity triggered by drug-modified HLA-peptide repertoire. Nature 2012;486: 554-558.

29 Ostrov DA, Grant BJ, Pompeu YA, Sidney J, Harndahl M, Southwood S, Oseroff C, Lu S, Jakoncic J, de Oliveira CA, Yang L, Mei H, Shi L, Shabanowitz I, English AM, Wriston A, Lucas A, Phillips E, Mallal S, Grey HM, Sette A, Hunt DF, Buus S, Peters B: Drug hypersensitivity caused by alteration of the MHC-presented self-peptide repertoire. Proc Natl Acad Sci USA 2012;109:9959-9964.

30 Norcross MA, Luo S, Lu L, Boyne MT, Gomarteli M, Rennels AD, Woodcock J, Margulies DH, McMurtrey C, Vernon S, Hildebrand $\mathrm{WH}$, Buchli R: Abacavir induces loading of novel self-peptides into HLA-B*57: 01: an autoimmune model for HLA-associated drug hypersensitivity. AIDS 2012;26:F21-F29.
31 Yun J, Adam J, Yerly D, Pichler WJ: Human leukocyte antigens (HLA) associated drug hypersensitivity: consequences of drug binding to HLA. Allergy 2012;67:1338-1346.

32 Illing PT, Vivian JP, Purcell AW, Rossjohn J, McCluskey J: Human leukocyte antigen-associated drug hypersensitivity. Curr Opin Immunol 2013;25:81-89.

33 Ko TM, Chung WH, Wei CY, Shih HY, Chen JK, Lin CH, Chen YT, Hung SI: Shared and restricted T-cell receptor use is crucial for carbamazepine-induced Stevens-Johnson syndrome. J Allergy Clin Immunol 2011;128: 1266-1276.

34 Wei CY, Chung WH, Huang HW, Chen YT, Hung SI: Direct interaction between HLA-B and carbamazepine activates $\mathrm{T}$ cells in patients with Stevens-Johnson syndrome. J Allergy Clin Immunol 2012;129:1562-1569.

35 Adam J, Eriksson KK, Schnyder B, Fontana S, Pichler WJ, Yerly D: Avidity determines Tcell reactivity in abacavir hypersensitivity. Eur J Immunol 2012;42:1706-1716.

36 Yun J, Marcaida MJ, Eriksson KK, Jamin H, Fontana S, Pichler WJ, Yerly D: Oxypurinol directly and immediately activates the drugspecific $T$ cells via the preferential use of HLA-B*58:01. J Immunol 2014;192:29842993.

37 Wuillemin N, Adam J, Fontana S, Krahenbuhl S, Pichler WJ, Yerly D: HLA haplotype determines hapten or $\mathrm{p}-\mathrm{i} \mathrm{T}$ cell reactivity to flucloxacillin. J Immunol 2013;190:49564964.

38 Winkler K, Winter A, Rueckert C, UchanskaZiegler B, Alexiev U: Natural MHC class I polymorphism controls the pathway of peptide dissociation from HLA-B27 complexes. Biophys J 2007;93:2743-2755.

39 Baratin M, Bonin K, Daniel C: Frontline: peripheral priming of alloreactive $\mathrm{T}$ cells by the direct pathway of allorecognition. Eur J Immunol 2004;34:3305-3314.

40 Adam J, Wuillemin N, Watkins S, Jamin H, Eriksson K, Villiger P, Fontana S, Pichler WJ, Yerly D: Abacavir induced $\mathrm{T}$ cell reactivity represents an allo-immune reaction. PLoS One 2014;9:e95339.

41 Golshayan D, Wyss JC, Buckland M, Hernandez-Fuentes M, Lechler RI: Differential role of naïve and memory CD4 T-cell subsets in primary alloresponses. Am J Transplant 2010;10: 1749-1759.

42 Macedo C, Orkis EA, Popescu I, et al: Contribution of naive and memory T-cell populations to the human alloimmune response. Am J Transplant 2009;9:2057-2066.

43 Lucas A, Lucas M, Strhyn A, Keane NM, McKinnon E, Pavlos R, Moran EM, MeyerPannwitt V, Gaudieri S, D’Orsogna L, Kalams S, Ostrov DA, Buus S, Peters B, Mallal S, Phillips E: Abacavir-reactive memory T cells are present in drug naïve individuals. PLoS One 2015;10:e0117160.

44 Felix NJ, Allen PM: Specificity of T-cell alloreactivity. Nat Rev Immunol 2007;7:942-953. 
45 Wucherpfennig KW, Allen PM, Celada F, Cohen IR, De Boer R, Garcia KC, Goldstein B, Greenspan R, Hafler D, Hodgkin P, Huseby ES, Krakauer DC, Nemazee D, Perelson AS, Pinilla C, Strong RK, Sercarz EE: Polyspecificity of $\mathrm{T}$ cell and $\mathrm{B}$ cell receptor recognition. Semin Immunol 2007;19:216-224.

46 von Greyerz S, Bultemann G, Schnyder K, Burkhart C, Lotti B, Hari Y, Pichler WJ: Degeneracy and additional alloreactivity of drug-specific human $\alpha \beta^{+} \mathrm{T}$ cell clones. Int Immunol 2001;13:877-885.

47 Correia O, Delgado L, Barbosa IL, Domingues JC, Azevedo R, Vaz CP, Pimentel P: CD8+ lymphocytes in the blister fluid of severe acute cutaneous graft-versus-host disease: further similarities with toxic epidermal necrolysis. Dermatology 2001;203:212-216.

48 Takeda H, Mitsuhashi Y, Kondo S, Kato Y, Tajima K: Toxic epidermal necrolysis possibly linked to hyperacute graft-versus-host disease after allogeneic bone marrow transplantation. J Dermatol 1997;24:635-641.

49 Friedman HZ, Arias AM, Catchatourian R, Fretzin DF: Toxic epidermal necrolysis following bone marrow transplantation. Cutis 1984;34:158-162.

50 Jeanmonod P, Hubbuch M, Grünhage F, Meiser A, Rass K, Schilling MK, Kollmar O: Graft-versus-host disease or toxic epidermal necrolysis: diagnostic dilemma after liver transplantation. Transpl Infect Dis 2012;14: 422-426.

51 Azukizawa H, Itami S: Animal models of toxic epidermal necrolysis; in Pichler WJ (ed): Drug Hypersensitivity. Basel, Karger, 2007, pp 129-139.

52 von Greyerz S, Zanni M, Frutig K, Schnyder B, Pichler WJ: Interaction of sulfonamide-derivatives with the TCR of sulfamethoxazole specific $\alpha \beta^{+}$T cell clones. J Immunol 1999; 162:595-602.
53 Schmid DA, Depta JP, Lüthi M, Pichler WJ: Transfection of drug specific $\mathrm{T}$ cell receptors into hybridoma cells: tools to monitor drug binding to TCR and to evaluate cross-reactivity to related compounds. Mol Pharmacol 2006; 70:356-365.

54 Depta JP, Altznauer F, Gamerdinger K, Burkhart C, Weltzien HU, Pichler WJ: Drug interaction with T-cell receptors: T-cell receptor density determines degree of cross-reactivity. J Allergy Clin Immunol 2004;113:519-527.

55 Burkhart C, Britschgi M, Strasser I, Depta JP, von Greyerz S, Barnaba V, Pichler WJ: Noncovalent presentation of sulfamethoxazole to human CD4+ T cells is independent of distinct human leucocyte antigen-bound peptides. Clin Exp Allergy 2002;32:1635-1643.

56 Zanni MP, von Greyerz S, Schnyder B, Wendland T, Pichler WJ: Allele-unrestricted presentation of lidocaine by HLA-DR molecules to specific $\alpha / \beta^{+} \mathrm{T}$ cell clones. Int Immunol 1998;10:507-515.

57 Watkins S, Pichler WJ: Activating interactions of sulfanilamides with $\mathrm{T}$ cell receptors. Open J Immunol 2013;3:139-157.

58 Watkins S, Pichler WJ: Sulfamethoxazole induces a switch mechanism in $\mathrm{T}$ cell receptors containing TCRV $\beta 20-1$, altering pHLA recognition. PLoS One 2013;8:e76211.

59 Pichler WJ, Watkins S: Interaction of small molecules with specific immune receptors: the $\mathrm{p}-\mathrm{i}$ concept and its consequences. Curr Immunol Rev 2014;10:7-18.

60 Schnyder B, Burkhart C, Schnyder-Frutig K, von Greyerz S, Naisbitt D, Pirmohamed M, Park K, Pichler WJ: Recognition of sulfamethoxazole and its reactive metabolites by drug specific $\mathrm{T}$ cells from allergic individuals. J Immunol 2000;164:6647-6654
61 Elsheikh A, Lavergne SN, Castrejon JL, Farrell J, Wang H, Sathish J, Pichler WJ, Park BK, Naisbitt DJ: Drug antigenicity, immunogenicity, and costimulatory signaling: evidence for formation of a functional antigen through immune cell metabolism. J Immunol 2010; 185:6448-6460.

62 Kohler J, Hartmann U, Grimm R, Pflugfelder U, Weltzien HU: Carrier-independent hapten recognition and promiscuous MHC restriction by $\mathrm{CD} 4 \mathrm{~T}$ cells induced by trinitrophenylated peptides. J Immunol 1997;158: 591-597.

63 Schnyder B, Adam J, Rauch A, Thurnheer MC, Pichler WJ: HLA-B*57:01+ abacavir-naive individuals have specific $\mathrm{T}$ cells but no patch test reactivity. J Allergy Clin Immunol 2013;132:756-758.

64 Strom BL, Schinnar R, Apter AJ, Margolis DJ, Lautenbach E, Hennessy S, Bilker WB, Pettitt $D$ : Absence of cross-reactivity between sulfonamide antibiotics and sulfonamide nonantibiotics. N Engl J Med 2003;349:16281635.

65 González-Martín G, Yañez CG, GonzálezContreras L, Labarca J: Adverse drug reactions (ADRs) in patients with HIV infection: a prospective study. Int J Clin Pharmacol Ther 1999;37:34-40.

66 Lin D, Tucker MJ, Rieder MJ: Increased adverse drug reactions to antimicrobials and anticonvulsants in patients with HIV infection. Ann Pharmacother 2006;40:1594-1601.

67 Jeffries M, Bruner G, Glenn S, Sadanandan P, Carson CW, Harley JB, Sawalha AH: Sulpha allergy in lupus patients: a clinical perspective. Lupus 2008;17:202-205.

68 Watkins S, Pichler WJ: T cell receptor variable $\beta 20-1$ harbors a nucleotide binding pocket in the CDR2 $\beta$ loop. Open J Immunol 2013;3: 165-174. 